\title{
Da cidade inteligente à inteligência nas operações urbanas: o caso do Centro de Operações Rio
}

\author{
From smart city to intelligence in urban operations: the \\ case of Centro de Operações Rio
}

\author{
Alexandre Hojda ${ }^{\mathrm{a}}$, Pedro Martins ${ }^{\mathrm{b}}$, Tharsila Maynardes Dallabona Fariniuk ${ }^{\mathrm{c}}$ \\ ${ }^{a}$ Centros de Comando e Controle urbanos (CCCs).profalexhojda@gmail.com. \\ b Centros de Comando e Controle Urbanos (CCCs). \\ pedro.martins@centrodeoperacoesrio.com.br. \\ c Universidade Católica do Paraná. tharsilamd@hotmail.com.
}

\section{RESUMEN}

A cidade do Rio de Janeiro possui peculiaridades geográfico-ambientais que, além de mundialmente conhecidas, são, também, parte de uma problemática urbana que vem exigindo cada vez mais atenção por parte dos governos. Os desafios urbanos pressionam a busca por uma postura inovadora dos governantes, assim como do cidadão. O Centro de Operações Rio (COR) foi criado com o objetivo de auxiliar na gestão das operações de infraestrutura e logística urbana da cidade, a partir da inserção de tecnologias modernas e da integração de mais de 30 agências públicas e concessionárias de serviços, em um mesmo espaço. É objetivo da pesquisa caracterizar as mudanças ocasionadas após a introdução do artefato tecnológico COR, identificando a aderência dessas transformações espaciais ao conceito de cidade inteligente. Busca-se, ainda, caracterizar a logística operacional, discutindo alguns dos preceitos teóricos presentes no conceito de cidade inteligente, e articulando as possíveis convergências entre essas premissas conceituais e as alterações observadas na cidade do Rio de Janeiro. Por fim, a pesquisa é um estudo de caso, baseada em Revisão Bibliográfica sistemática (RBS), entrevistas semiestruturadas e participação-observante.

Palabras clave: Smart cities; Centro de Operações Rio; governança urbana; resiliência urbana; operação urbana

\begin{abstract}
The city of Rio de Janeiro has geographic-environmental peculiarities which are world-renowned, and which are also part of an urban problem that demands more and more attention from the government. Urban challenges are pressing for an innovative attitude of government, as well as of its citizens. Centro de Operações Rio (COR) was created to support the management of the urban infrastructure and logistics operations in the city, by applying modern technologies and the integration of more than 30 public agencies and other utilities services providers, all in the same area. This research aims to characterize the changes occurred in the city of Rio de Janeiro after the introduction of the technological artefact COR, identifying an adherence with spatial transformations and the concept of smart city. We also try to characterize the operational logistics, discussing some of the theoretical precepts of the concept of smart city, in enforcement mechanisms in the implementation and operationalization of COR, and articulating as possible convergences between these preconceptions and that which we observed in the city of Rio de Janeiro. Finally, the
\end{abstract}


research is a case study, based on Systematic Literature Review (SLR), semi-structured interviews and participant-observation.

Keywords: Smart Cities; Centro de Operações Rio; Urban Governance; Urban resilience; Urban operation

\section{INTRODUÇÃO}

A cidade do Rio de Janeiro possui peculiaridades geográfico-ambientais que, além de esteticamente agradáveis e mundialmente conhecidas, a posicionam de maneira particular em relação ao restante do Brasil e que são, também, parte de uma problemática urbana que vem exigindo cada vez mais atenção por parte do poder público.

Com características bastante heterogêneas, parte dos mais de seis milhões de habitantes ocupa áreas não adequadas para moradia. Diversos aspectos socioculturais e históricos transformaram a cidade em um espaço também conhecido pela inadequação habitacional e pela violência. Esse cenário agrava-se com políticas públicas muitas vezes descontinuadas e que nem sempre contaram com planejamento de longo prazo. Os desafios urbanos pressionam a busca por uma postura inovadora dos governantes, em planejamento e gestão (demandas crescentes versus orçamentos restritos), assim como do cidadão, que necessita viver em um espaço urbano cada vez mais acirrado, cujos serviços públicos, por vezes, não atendem totalmente às demandas da população.

Além disso, a cidade apresenta uma histórica vulnerabilidade a desastres naturais e geotécnicos decorrentes de fatores ocupacionais, geológicos e topográficos, acentuados com a intensificação da urbanização no século XX. Esse processo, associado às questões sociais já comentadas indicam a demanda por um planejamento integrado de busca por mais igualdade e otimização de recursos (Nacaratti, 2008). Nesse cenário a relação cidade e tecnologia pode ser um caminho para melhorar a capacidade de resposta da gestão, materializando o fenômeno "cidade informacional", que enfatiza a incorporação do uso da informação e das Tecnologias de Informação e Comunicação (TIC) na gestão urbana. Mais recentemente, o termo cidade inteligente, ou smart city emergiu no sentido de atualizar esse conceito, associando a utilização das tecnologias a outros interesses urbanos, como a segurança, a saúde, a educação e a preservação do meio ambiente.

$\mathrm{O}$ contexto aponta que diversos projetos vêm sendo implantados em cidades brasileiras e do exterior, visando a otimização das infraestruturas para um melhor atendimento do cidadão. Um exemplo é a implantação do Centro de Operações da Prefeitura do Rio de Janeiro (COR), criado no final de 2010 com o objetivo de auxiliar a gestão operacional da cidade. Este Centro de Comando e Controle -que também será referenciado com a sigla "CCC" neste texto- é composto por tecnologias modernas para gestão integrada das operações de infraestrutura, logística e emergências urbanas. Em termos operacionais, o COR integra mais de 30 agências e concessionárias de serviços, ligadas às esferas federal, estadual e municipal, as quais, utilizam Tecnologias da Informação e Comunicação (TIC) para apoiar a tomada de decisão sobre as ações de tráfego urbano, intempéries, emergências, deslocamentos, segurança, momentos de crise, logística de megaeventos, entre outras. 
Nos últimos anos, a cidade do Rio de Janeiro passou por uma série de eventos que alteraram profundamente a dinâmica urbana, como a Conferência das Nações Unidas sobre Desenvolvimento Sustentável (Rio+20), em 2012; a Jornada Mundial da Juventude (JMJ), em 2013; os jogos da Copa do Mundo FIFA, em 2014; e os Jogos Olímpicos de 2016. Esses eventos, associados a ocorrências sazonais (como deslizamentos de terra durante o período anual de chuvas fortes, no verão) e às dinâmicas urbanas cotidianas constituem o contexto de atuação do COR.

O COR, inicialmente criado a partir de ações de parcerias público-privadas, fomentou um processo de construção de relações sociotécnicas e de reorganização de processos da gestão das operações urbanas do município, colaborando para agilizar as respostas e conferindo maior potencial de previsibilidade para as ocorrências. Este processo, cujas frentes de trabalho têm uma intensa característica de integração entre todos os atores da operação urbana, sugere transformações nos mecanismos da gestão urbana do município do Rio de Janeiro.

Em consideração a esse contexto, questiona-se de que forma o COR impactou a gestão da cidade do Rio de Janeiro desde o momento de sua implementação. O presente trabalho visa caracterizar as mudanças ocasionadas na cidade do Rio de Janeiro após a introdução do artefato tecnológico COR, identificando a aderência dessas transformações espaciais ao conceito de cidade inteligente. Além disso:

- i) caracterizar o processo de implantação e funcionamento do COR, em termos de logística operacional, recursos (humanos, materiais, tecnológicos, etc.) e estratégias de ação.

- ii) discutir alguns dos preceitos teóricos presentes no conceito de cidade inteligente, em consideração aos mecanismos utilizados na implementação e operacionalização do COR.

- iii) articular e analisar as possíveis convergências entre as premissas conceituais e as alterações observadas na cidade do Rio de Janeiro.

O texto está estruturado de maneira a responder a cada um desses objetivos em sequência, inicialmente, e posteriormente articulando-os um com os outros. Desta maneira, o próximo item tratará do conceito de cidade inteligente e definições correlatas. Em seguida, será apresentada uma discussão teórica sobre os centros de comando e controle, além da apresentação e caracterização do caso estudado. $\mathrm{Na}$ sequência, será apresentada a metodologia, baseada em Revisão Bibliográfica Sistemática (RBS), entrevistas semiestruturadas e participação-observante, seguida pela apresentação e discussão dos resultados. Por fim, vêm as conclusões do estudo e considerações finais.

\section{CidAdES INTELIGENTES}

O termo cidade inteligente é uma denominação de uso relativamente recente, que surgiu como uma forma de atualização de conceitos anteriores como "cidade virtual" e "cidade digital". Todas essas denominações indicam cidades que fazem uso de TICs para automatização ou aprimoramento de serviços e operações urbanas. Esse processo pode incluir ferramentas como smartphones, aplicativos, digitalização de dados e processos e sistemas de monitoramento de dados com base em inteligência artificial, big data e internet das coisas. Cidade inteligente é a tradução literal do termo smart city, embora a palavra inteligente não traduza em totalidade 
a amplitude da palavra smart. Esta pesquisa, no entanto, adotará a denomina ção em português.

Pode-se observar uma certa divergência no entendimento de quando começou-se a falar sobre cidades inteligentes. Na segunda metade da década 2000, a expressão cidade inteligente passou a ser amplamente usada por empresas privadas de tecnologia, tais como a IBM, Cisco, Siemens etc., associando esse conceito a produtos que foram apresentados como solução para as cidades. Segundo Komninos (2011), no entanto, os primeiros estudos datam do início da década de 1990, e consideravam a tecnologia e os assuntos emergentes na época, tais como a implantação de pólos tecnológicos. De acordo com Llacuna et al. (2015), o conceito só passou a ser mais amplamente divulgado em meados de 2009.

Na compreensão mais recente, cidades inteligentes são consideradas aquelas que investem em infraestrutura e instrumentação digital, as quais geram diversos efeitos sociais, técnicos e espaciais. No entanto, não devem ser consideradas como cidades futurísticas, tão presentes no imaginário coletivo, mas sim como redes urbanas cada vez mais complexas que podem ser gerenciadas pela tecnologia (Kitchin, 2014).

Embora essa concepção esteja, de maneira geral, presente na maioria dos estudos sobre cidades inteligentes, ultimamente os autores vêm incluindo outros elementos no conceito, tornando a discussão ainda mais abrangente e complexa. Neste sentido, o conceito passa por alguns desdobramentos teóricos.

Kitchin (2014) e Holland (2008) afirmam que as cidades inteligentes podem ser caracterizadas em duas esferas: em primeiro lugar, a partir da utilização das TICs propriamente dita e dos dados, e, em segundo lugar, a partir do capital humano (a relação das TICs com o conhecimento, a educação e qualificação). Essas duas esferas também estão presentes no entendimento de Klauser et al. (2014) sobre o conceito de cidade inteligente, que acrescenta, ainda, um terceiro espectro de discussão: a interligação entre os dados, a tecnologia e as pessoas, num processo de reorganização. Essa combinação de diversos fatores está presente também nos entendimentos de:

- Toppeta (2010), segundo o qual a reorganização de processos, a partir da inserção das tecnologias, contribui para o gerenciamento inovador e para a redução da burocracia.

- Caragliu et al. (2011), que entendem o conceito como sendo o resultado de uma soma entre infraestruturas digitais e físicas, infraestruturas sociais (capital humano) e capital social (participação).

- Nam \& Pardo (2011), os quais afirmam que a cidade inteligente enfatiza os fatores tecnologia (infraestruturas de hardware e software), pessoas (criatividade, diversidade e educação) e institucional (governança e política).

Um dos conceitos de cidade inteligente mais difundidos na literatura, no entanto, é o da Universidade Tecnológica de Viena (TUWIEN European Smart Cities, 2016), que detalha ainda mais essa combinação de fatores. De acordo com a publicação, cidade inteligente é fruto de um processo de inteligenciamento urbano em seis áreas: a governança, a economia, o bem-estar urbano, a mobilidade, o meioambiente e as pessoas. Esses dois últimos aspectos, em especial, vêm sendo cada vez mais destacados em discussões sobre cidades inteligentes. 
De acordo com Steenbruggen et al. (2014) a sustentabilidade ambiental é fundamental para a construção de uma cidade inteligente, uma vez que é indispensável pensar na gestão racional dos recursos. Isso está diretamente relacionado com o uso das tecnologias, pois o processo demanda dados e informações sobre o uso dos recursos naturais e das estruturas urbanas. Segundo os autores, o processo de coleta e análise dos dados pode resultar em melhorias na capacidade de resposta das cidades e em um incremento na qualidade de vida do cidadão.

A ênfase no cidadão também é fundamental neste processo, segundo Giffinger et al. (2007). O autor afirma que a busca pela inteligência urbana deve combinar o esforço por um bom desempenho a estímulos educacionais. Citrigno et al. (2014) reforça esta ideia afirmando que aspectos ligados a inclusão e capacitação dos cidadãos e dos agentes envolvidos na operação da cidade são fundamentais para a inteligência urbana. Ambos os grupos, de acordo com os autores, devem tornar-se os principais tutores do território, sendo como "sensores sociais" (p.42) para o processo de empoderamento, cujo resultado é a elevação da participação cidadão na detecção de situações críticas no território urbano.

É importante ressaltar, ainda, a contribuição de dois autores que tratam das "lições aprendidas" em iniciativas e projetos para cidades inteligentes. De acordo com Money \& Cohen (2015) as políticas devem ser avaliadas por meio do aprimoramento constante. Isso é fundamental para a complexa rede de sistemas e partes envolvidas em uma cidade inteligente, pois auxilia a aumentar a confiança no sistema e a reduzir o tempo nas respostas. Além disso, é importante também para que a equipe possa ampliar sua capacidade analítica e de comparação. Ching \& Ferreira Jr. (2015), por sua vez, colocam esse processo de aprendizado e aprimoramento na utilização das ferramentas tecnológicas e no envolvimento do cidadão. Segundo os autores, as "lições aprendidas" são relevantes trabalhos e retrabalhos com os dados para entender as ações e os processos, de forma a minimizá-los ou evitar que determinados fatos aconteçam novamente. Dessa forma, valoriza-se a capacidade da governança local de internalizar conhecimento via estudo dos dados, aperfeiçoando os protocolos e as respostas futuras.

O papel da gestão urbana nesse processo, no entanto, ainda é uma lacuna a ser preenchida na literatura. Faz-se necessário mais estudos para compreender quais são as áreas de maior participação e interesse da gestão urbana dentro do âmbito das cidades inteligentes, especialmente no que refere ao discurso sobre o conceito versus as iniciativas implementadas (Alizadeh, 2017).

Xu e Geng (2019) comentam que o inteligenciamento urbano advém de um processo em três camadas, que são a infraestrutura física, a gestão de dados e a oferta de serviços. Essa última camada depende fundamentalmente da inteligência gerada entre os grupos, especialmente a partir da detecção de possíveis demandas futuras e do tratamento a partir da previsão desses comportamentos. Para os autores, ser inteligente nesse processo denota oferecer serviços de maneira personalizada às demandas, com respostas velozes e gestão do conhecimento de forma a antecipar as condições do contexto.

$\mathrm{Na}$ América Latina isso toma especial forma, uma vez que as demandas para inteligenciamento urbano acompanham demandas comuns à maior parte dos locais em processo desenvolvimento. Segundo Calderón, López e Marín(2018), de modo 
geral, os países latino-americanos possuem desafios referentes à gestão urbana propriamente dita, aos recursos financeiros limitados, limitado acesso tecnológico e relevante parte dos dados ainda sem o foco na digitalização, o que constitui uma problemática no pleno desenvolvimento dos modelos mais disseminados para smart cities. No entato, tal cenário pode ser também uma oportunidade para incremento do bem-estar urbano e desenvolvido em geral, impulsionado pelas TICs.

Nesse contexto, é difícil para as cidades latino-americanas se tornarem inteligentes, mas esses desafios podem ser vistos como oportunidades para melhorar a qualidade de vida de suas populações por meio da implementação de iniciativas inteligentes impulsionadas pelas TIC (Calderon; Lopez; Marin, 2018).

De modo geral, no Brasil a utilização da nomenclatura smart city serve a projetos que são veiculados e patrocinados por empresas desenvolvedoras de tecnologias, e também por meio da disseminação em exposições e eventos internacionais -a exemplo do Smart City Business (Smart City Business, 2020). O conceito também vem sendo cada vez mais utilizado por startups associadas à ideia da inovação e pelos próprios municípios que se auto entitulam "inteligentes", sem necessariamente passar por algum tipo de análise (externa) ou certificação.

Entre as iniciativas da temática que se pode destacar no país estão a Rede de Cidades Inteligentes e Humanas, composta por 16 cidades associadas a entidades internacionais, a ABDI -Associação Brasileira de Desenvolvimento Industrial-, que possui um setor voltado para o desenvolvido de TICs e serviços para smart cities, e o Programa Cidade Sustentáveis, que define agendas e atribuições para as prefeituras (CUNHA et al., 2016).

\section{VIGILÂNCIA E CONTROLE NAS CIDADES INTELIGENTES: OS CENTROS DE COMANDO E CONTROLE (CCCS)}

$\mathrm{O}$ processo de vigiar, monitorar e controlar existe nas cidades desde o princípio da humanidade, acompanhar o desenvolvimento e a evolução humana e tecnológica. Assim, a vigilância também passa por um processo de inteligenciamento, sendo até mesmo assim denominada vigilância inteligente, ou smart surveillance (Hampapur et al., 2003). Segundo Bruno (2013), a vigilância inteligente ocorre quando o ato de vigiar é realizado por meios de tecnologias inteligentes que podem atuar diretamente sobre o meio. Esse é um processo que pode ocorrer em tempo real, a partir da decodificação de algoritmos que podem ser pré-determinados para identificação automática, detecções específicas e tratamento de ocorrências (Durães, 2008). Ou seja, a vigilância inteligente nada mais é do que um aprimoramento tecnológico da vigilância, monitoramento e controle tradicionais (Batista et al., 2016).

Dentro da lógica de materialização da cidade inteligente, uma ferramenta disponível (mas ainda pouco utilizada na gestão urbana brasileira), é o uso dos Centros de Comando e Controle (CCC), também denominados de centro de operações. O objetivo de um CCC é reunir dados, ferramentas e pessoas para a construção da inteligência urbana, resultando em um aumento da fluidez da cidade e na resolução de problemas no menor tempo possível (Kanashiro, 2009).

Um CCC apresenta um ambiente provido de tecnologias (com informações em tempo real e integradas ao sistema), ferramentas e infraestrutura, permitindo aos 
agentes supervisionar, controlar e interagir. A lógica dos centros de operações consiste em que todos os integrantes devem saber sobre a atuação dos demais envolvidos, contribuindo tanto para uma possível divisão de tarefas, quanto para a cooperação (Queiroz, 2010; Couto \& Soares, 2012).

No CCC, a dinâmica de monitoramento amplia a capacidade de vigilância (um operador pode acompanhar várias câmeras ao mesmo tempo), e a tecnologia de softwares permite uma otimização ainda maior desse trabalho (câmeras inteligentes alertam para imagens fora da normalidade, como pacotes abandonados, presença de pessoas em locais estranhos, identificação de determinados indivíduos na multidão mediante análise de dados biométricos ou carros andando na contramão em uma rodovia) (Cardoso, 2010).

\section{Descrição do CAso: o Centro de Operações Rio (COR)}

A partir da perspectiva dos megaeventos ocorridos na cidade do Rio de Janeiro entre 2013 e 2016, a cidade viveu um momento singular e atípico de favorável relação entre os três níveis de governo, no sentido de viabilizar mudanças na dinâmica urbana e assim projetar internacionalmente a imagem da cidade do Rio de Janeiro. Com a aproximação dessas situações urbanas, as esferas de gestão almejavam uma projeção urbana não apenas referente às já disseminadas estéticas naturais e musicais da cidade, mas também como uma cidade dotada de infraestrutura, recursos e pessoas capazes de desenvolver e acolher grandes projetos, criar soluções inovadoras e construir experiências de sucesso.

Uma das iniciativas desenvolvidas para este fim foi a implantação do Centro de Operações Rio (COR), em 31 de dezembro de 2010. O espaço foi projetado para ser um local de gerenciamento de respostas integradas às emergências vivenciadas pela cidade, minimizando impactos e salvando vidas, além de cuidar das operações da rotina da cidade ou em situações especiais, como os megaeventos.

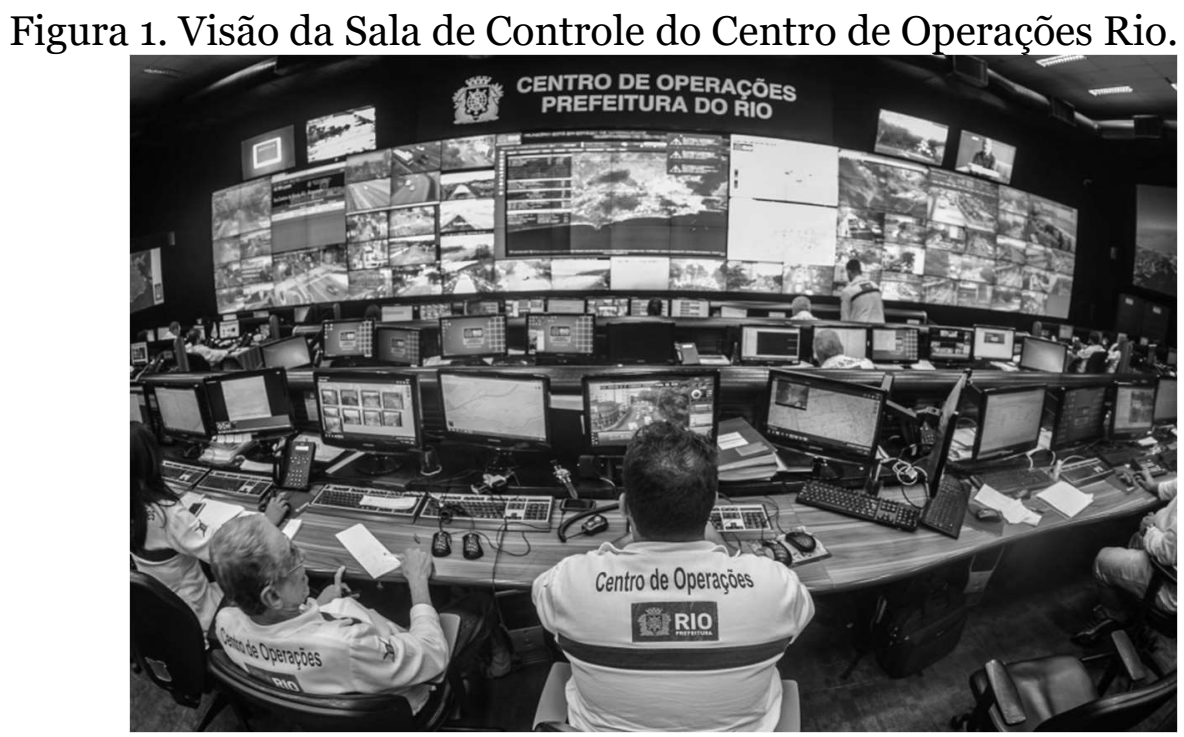

Fonte: Divulgação / Centro de Operações Rio.

A implantação do COR ocorreu a partir da integração das esferas de gestão, que resultou na criação de uma equipe com representantes de agências de serviços 
públicos operando em um mesmo ambiente (a Sala de Controle do COR, vide Figura 1). Este ambiente foi estruturado de modo a permitir integração tecnológica de dados e informações, de processos e de pessoas, advindos dos diferentes órgãos e departamentos integrados.

Atualmente o espaço concentra representantes de mais de 30 agências e concessionárias de serviços públicos, sendo a maioria da esfera municipal, como a companhia municipal de tráfego, o deparmento de meteorologia e outros órgãos que gerenciam operações de ordem pública, conservação, rios e lagos, meio ambiente, transporte, defesa civil, iluminação e limpeza urbana, turismo, dentre outras.

Para monitorar a cidade em tempo real, a infraestrutura do COR é composta por:

- Aproximadamente 800 câmeras municipais distribuídas em toda a cidade (associadas a equipamentos de instituições parceiras, esse número chega a 1000).

- Um radar meteorológico municipal.

- Aparelhos de GPS instalados em ônibus e veículos municipais.

- Diversos outros sensores que fornecem dados como condições de tráfego, intensidade de chuvas, nível de lagoas e rios.

A conexão entre diferentes tipos de dados é estabelecida na Sala de Controle, a partir da visualização em um videowall, onde é possível observar cruzamentos de mais de 250 camadas de informação, detalhadas para cada região e cada serviço da cidade, operando 24 horas por dia, nos 7 dias da semana (conceito 24/7).

O COR está articulado com vários canais de troca de informações com a sociedade. Entre eles, pode-se citar o estreito relacionamento com os meios de comunicação, os perfis nas redes sociais gerenciados 24/7 (principalmente no Twitter e Facebook), a Central 1746 (telefone unificado de atendimento ao cidadão carioca), além de integrações com aplicativos de mobilidade urbana, como o Waze e Moovit. Com informações da equipe de meteorologia da prefeitura, que opera dentro do COR, a Defesa Civil municipal gerencia serviços de emergências, como o sistema de alerta por sirene (para áreas de risco) e comunicação com envio de mensagens de texto (SMS) via celular.

O COR destaca-se também por estar inserido em uma perspectiva mais mercadológica da noção de cidade inteligente, por ser um projeto iniciado em parceria com a IBM. De acordo com reportagem do jornal Folha de São Paulo (2012),

Aberto pela unidade de Cidades Mais Inteligentes da empresa no final de 2010, o Centro de Operações Rio faz parte de um esforço para conquistar um lugar nesse mercado. Desde sua fundação, a unidade Cidades Mais Inteligentes já se envolveu em milhares de projetos.

Esta é uma perspectiva vista com ressalvas por alguns autores, uma vez que neste caso a construção do conceito de cidade inteligente não está voltada apenas para o planejamento urbano, mas torna-se também produto, aproveitado pelos mais diversos setores. De acordo com Harvey (2005), a noção de cidade inteligente passa a ser considerada como cidade "empreendedora" (entrepeneur city), ou seja, como uma cidade que busca desenvolvimento a partir de um modelo empresarial de livre concorrência. Isso pode ocorrer a partir de: a) parcerias público-privadas, b) especulação, natural dos processos empreendedores, e c) um destaque para 
economia política em detrimento às condicionantes territoriais, tendencialmente justificado pelo discurso público como ação para melhoria da imagem urbana.

\section{Metodologia}

Este texto é parte de uma pesquisa mais abrangente, que visa estudar a construção sociotécnica do Centro de Operações Rio perante as relações entre pessoas, tecnologias e instituições. $\mathrm{O}$ texto apresenta uma pesquisa realizada em forma de estudo de caso, ou seja, visando contextualizar um fenômeno sob múltiplos aspectos e responder questões sobre sua causalidade (Yin, 2001). O recorte temporal estabelecido é o período compreendido entre os anos de 2011 e 2016.

Na organização do estudo foi realizada uma Revisão Bibliográfica Sistemática (RBS), sem fins estatísticos ou quantitativos e com foco na construção teórica do presente artigo, a qual permite o levantamento de evidências e informações que possam contribuir com processos construção do entendimento do tema específico estudado, evitando, assim, possíveis vieses que o pesquisador possa ter no momento da análise (Botelho et al., 2011). Na sequência utilizou-se entrevistas semiestruturadas e coleta de dados via participação observante.

Dessa maneira, um primeiro momento de pesquisa visou levantar o arcabouço teórico-literário existente sobre a temática. Foram selecionados cinco portais de pesquisa acadêmica: Google Scholar; Research Gate; Academic.Edu; Read Club; e Science Direct. E três portais de periódicos: Portal de Periódicos da CAPES; Redalyc; e Scielo.

Nestas fontes foram coletados os artigos provenientes da busca pelas seguintes palavras-chave (sozinhas ou associadas):

- "gestão urbana" + "tecnologia" + "TICs";

- "cidade inteligente";

- "smart city";

- "CCC";

- "sala de controle";

- "sala de situação";

- "sala de crises";

- "Big Data";

- "COR".

Coletou-se nesta etapa um total de 93 textos, que foram na sequência filtrados por aderência ao tema e capacidade de contribuição à pesquisa.

A segunda etapa da metodologia envolveu as entrevistas semiestruturadas. Esse modelo de entrevista possibilita caminhos para o entrevistado responda de forma mais satisfatória, tendo em vista as perguntas de pesquisa e objetivos. De acordo com Gil (2008), este tipo de entrevista permite a fala livre sobre o assunto, ao mesmo tempo em que força o entrevistador a conhecer os diversos aspectos do assunto em pauta.

As entrevistas semiestruturadas foram realizadas no segundo semestre de 2015 com atores-chave ligados ao COR. A seleção de entrevistados ocorreu com apoio da técnica Bola de Neve, a qual é determinada pelo processo de indicação do entrevistado com outros nomes que possam contribuir com a pesquisa. De acordo com Dragan e Maniu (2013), essa técnica apresenta diversas vantagens para a 
pesquisa qualitativa por dar a possibilidade ao pesquisador para trabalhar em áreas que não se apresentam expressivas de forma estatística. A descrição anonimizada dos atores entrevistados pode ser observada no Quadro 1.

Quadro 1. Descrição dos entrevistados.

\begin{tabular}{|r|l|l|}
\hline Perfil & Função / cargo & Envolvimento com o COR \\
\hline 1 & Funcionário público & $\begin{array}{l}\text { Projeto; implementação e } \\
\text { funcionamento }\end{array}$ \\
\hline 7 & Funcionário público & Funcionamento \\
\hline 10 & Profissional do setor privado & Funcionamento \\
\hline 11 & Profissional do setor privado & Projeto e implementação \\
\hline 12 & Funcionário público & Projeto e implementação \\
\hline 13 & Acadêmico & Funcionamento \\
\hline 14 & Terceirizado que trabalha no COR & Implementação e funcionamento \\
\hline 16 & Profissional do setor privado & Projeto; implementação \\
\hline 18 & Profissional do setor privado & Funcionamento \\
\hline 19 & Profissional do setor privado & Funcionamento \\
\hline 20 & Terceirizado que trabalha no COR & Funcionamento \\
\hline 24 & Profissional do setor privado & Funcionamento \\
\hline 25 & Profissional do setor privado & Implementação e funcionamento \\
\hline 27 & Funcionário público & $\begin{array}{l}\text { Projeto; implementação e } \\
\text { funcionamento }\end{array}$ \\
\hline 33 & Funcionário público & Implementação e funcionamento \\
\hline 37 & Funcionário público & Implementação e funcionamento \\
\hline
\end{tabular}

Fonte: elaborado pelos autores.

As questões orientativas das entrevistas relacionam-se especialmente com os seguintes assuntos: criação do COR; relações institucionais; relação da prefeitura com o setor privado; mudanças na gestão municipal com a implantação do projeto COR; capacidade de replicação do projeto e lições aprendidas.

A terceira fase de pesquisa foi realizada em forma de participação observante (Wacquant, 2002), permitindo o aprimoramento da análise. Essa observação ocorreu no período compreendido entre outubro de 2015 e setembro de 2016, e foi realizada por um pesquisador em fase de doutorado (visitas técnicas e conversas informais) e um profissional atuante no COR.

A análise de resultados visa responder aos objetivos da pesquisa, que envolve a convergências entre as premissas conceituais e as alterações observadas na cidade do Rio de Janeiro a partir da implementação do COR. Inicialmente, foram listadas as mudanças observadas na cidade neste período e na sequencia são trabalhadas essas alterações perante as premissas teóricas presentes na relação de autores estudados e das entrevistas realizadas. Cada um dos itens dessas listas fora analisado em combinação, buscando identificar congruências e controvérsias entre a teoria e o caso prático. 


\section{ANÁLISE DE RESULTADOS}

Com a implantação do COR no Rio de Janeiro, importantes mudanças aconteceram na estrutura da gestão municipal e no próprio comportamento dos agentes públicos envolvidos nas operações da cidade. Caragliu et al. (2011) afirmam que entre as transformações geradas na cidade inteligente está o fortalecimento da tecnologia, da gestão pública, dos fatores institucionais e da qualificação da mão de obra, bem como a necessidade de redução da burocracia, de integração dos processos e de participação pública. Correlacionando os destaques dos autores com a realidade observada, os pontos assinalados pelos autores são tópicos que em sua maioria sofreram relevantes transformações com a construção do COR.

Os itens a seguir foram organizados de forma a elencar quatro pontos fundamentais de mudança possibilitadas pela tecnologia e pelas ações desenvolvidas acerca delas, em observação à literatura estudada (Figura 2). Os quatro pontos foram abordados evidenciando trechos de entrevistas e reportagens, nas quais se busca identificar aspectos positivos e negativos, bem como benefícios e dificuldades de cada uma dessas transformações.

Figura 2. Quatro eixos de transformação analisados.



Fonte: elaborado pelos autores.

\subsection{Atuação multiagência}

Intitulada de "O Big Brother do Prefeito”, a reportagem da Revista Veja Rio de 09 de fevereiro de 2011, apresenta como destaque a Sala de Controle onde os representantes dos diversos departamentos e serviços atuam em regime 24/7. Esta construção da integração objetiva resolver as demandas da cidade no menor tempo de resposta possível e com otimização dos recursos empregados.

Antes da implantação do COR, o monitoramento das situações urbanas era majoritariamente feito dentro de cada agência, com cada equipe focando apenas nas especificidades de seu próprio setor, como ocorre na maioria das cidades. Em caso 
de necessidade de apoio de outras equipes, o próprio setor buscava pontualmente essa participação. Essa dispersãofica evidente em trechos de alguns dos entrevistados:

$\mathrm{O}$ prefeito [...] entendeu que ele precisava de um local para fazer o gerenciamento da cidade, com 'todos e tudo', todas as informações, tudo em um único local. Os órgãos da prefeitura até então estavam todos dispersos, cada um trabalhando isolado e com as suas informações; e pouco se conhecia do outro órgão. Cada órgão ficava fisicamente isolado, cada um no seu prédio, praticamente independente. Esse isolamento prejudicava, por exemplo, em uma situação de crise, pois eram dois esforções [sic], superar as crises. Mas antes tinha que juntar, agregar, aglutinar todos esses atores envolvidos, que estavam dispersos; agora estão aglutinados e interagindo. (Entrevistado Perfil 01, 2015).

Antes do COR, todo contato era muito mais difícil. Tudo era disperso. Hoje é tudo integrado, eu estou sentado aqui ligo direto para a minha pessoa dentro do COR e imediatamente ele fala com a pessoa do outro departamento dentro do COR. Muito rápido e fácil. Antes tudo disperso, liga para um, liga para outro... (Entrevistado Perfil 24, 2015).

Na Sala de Controle do COR, as ocorrências são tratadas sob a perspectiva das características do problema identificado. Essas características é que orientam o tipo de decisão a ser tomada para solucionar a ocorrência. Não é mais uma questão de a agência fazer o que lhe cabe, mas sim de quais são os recursos necessários para resolver $o$ fato, quais agências devem ser acionadas para prover tais recursos/serviços e qual é a melhor forma destas agências atuarem conjuntamente. Desta forma -com representantes das agências operando em um mesmo ambiente de trabalho, com maior grau de conhecimento sobre as operações umas das outras-, o COR consegue elevar o grau de engajamento e coordenação dos atores, que passam a enxergar os problemas de uma maneira mais ampla e integrada. A experiência de integração dos representantes de agências dentro do COR permite que todos conheçam de forma mais abrangente as operações de cada órgão, o que aprimora a tomada de decisão na resposta aos problemas da cidade. Integradas no COR, as agências não mais se comunicam bilateralmente, mas sim multilateralmente. Os trechos a seguir sugerem o reconhecimento dos benefícios da integração:

O COR não cria nada: ele é inovador em integrar. Integrar informações. Integrar atores. (Entrevistado Perfil 16, 2015).

Um dos grandes destaques do COR é que os atores estão juntos, na hora que se põe os atores para conviver, isso gera um resultado muito positivo, pois um vai conhecendo o outro e vão crescendo em relações e apoios. (Entrevistado Perfil 07, 2015).

(O grande destaque) colocar os agentes para trabalhar junto. Até se desse apenas papel e caneta já iria ter ganhos de ter os atores trabalhando junto... [...] Aproxima, quebra barreiras, ganha confiança, cooperação. Só por essa iniciativa de juntar todos na mesma sala já teria valido a pena, mesmo com papel e caneta.... (Entrevistado Perfil 25, 2015). 
As relações são pessoais, serão sempre pessoais, então a proximidade física ajuda a melhorar as relações pessoais, e resolve muitos problemas de gestão. Quando esses órgãos ficam separados, cai a interação, a sinergia, de processos. 80\% dos [...] problemas vão resolver aproximando as pessoas (Entrevistado Perfil 33, 2015).

Hoje tem muitas tecnologias e câmeras ajudando a gerir a cidade, pois geram muitos dados e informações "24/7". O COR sendo um centro de controle de gestão da cidade que reúne atores deve estimular o compartilhamento dos dados e o apoio mútuo de forma à termos um 'duplo apoio': 'eu tenho mais informações, eu ajudo ele a se prevenir, e ele me ajuda a me prevenir'. (Entrevistado Perfil 01, 2015).

A gestão multiagências envolve a interligação entre os dados, as tecnologias e os departamentos, sendo necessário reorganizar os processos de reorganização, um processo que pode ser dividido em duas partes: primeira colando integração de dados e a segunda nas ações para integrar as pessoas. Nesse sentido Nan e Pardo (2011) corroboram enfatizando que a interligação entre os fatores de tecnologia (infraestruturas de hardware e software), pessoas e instituições contribui para o gerenciamento inovador e Toppeta (2010) aponta a redução da burocracia como o grande ganho da relação multiagência.

Atuação integrada não teve fácil aceitação dos departamentos. O início do trabalho do COR causou um incômodo para os departamentos, eles tiveram que sair da sua estática, sair da sua área de conforto. Recordo que eu conversava com um e com outro departamento e sentia muita resistência por parte deles sobre essa integração e mesmo sobre colocar um homem na sala de situação se expondo e expondo o departamento. Quando eu me exponho eu mostro minha fragilidade. (Entrevistado Perfil 11, 2015).

(Havia) uma resistência inicial, cada uma ficava no seu mundinho e era difícil pensar em sair do seu conforto. Muitos pensavam: 'posso perder poder'; 'posso perder autonomia'. Mas depois que se mostrou o valor agregado que aquilo traria, o ganho para todos, com o amplo acesso à cooperação e às informações... isso favoreceu a [...] um colaborar com o outro, se perdeu o medo de se expor. [...] O grande destaque do COR é a integração entre os atores. Hoje as secretarias conseguem perceber que o COR aumenta o valor agregado para o trabalho delas! (isso é um aprendizado e um ganho, até difícil de mensurar!). Passo a ver o COR como um ganho para minha secretaria, um ganho pois tenho mais informações e mais parceiros (Entrevistado Perfil 12, 2015).

COR é instância de integração, não tem autoridade, ele força o entendimento, expõe o problema. O COR força a ação, e isso gerou muita briga no início. [...] No início as dificuldades foram grandes, pois em geral os secretários são políticos, e não técnicos para entender os desafios. Daí tem problemas de 'puxa saco', pouca eficiência, pouca integração. (Entrevistado Perfil 13, 2015).

O COR consegue reunir trinta e tantos atores juntos! No começo tinha resistência dos atores, das secretarias em atuar junto. Muitas inicialmente não tinham essa cultura de dividir conhecimento dos seus processos e não 
acreditavam que o COR iria vingar, ou seja, 'não vou dar muita bola para essa nova demanda, pois vou só perder meu tempo e depois esse CCC não vinga. Perdi tempo, recurso, homem e energia e ainda vou me expor...' (Entrevistado Perfil 14, 2015).

A fim de viabilizar a organização das estratégias na atuação conjunta, todas as ações são supervisionadas por um profissional denominado "coordenador da Sala de Controle". O papel deste ator é enxergar os problemas de maneira macro, avaliando continuamente os impactos das ocorrências na rotina da cidade e do cidadão, e tomando as medidas necessárias para que as respostas sejam as mais efetivas possíveis. A respeito dessa função, os entrevistados destacam:

[...] Posição fundamental. Ele faz o trabalho de ajeitar as relações entre os atores no teatro de atores, na relação entre os órgãos. Ele é um facilitador de pessoas e processos [...]. Regula a temperatura no teatro de atores. (Entrevistado Perfil 07, 2015).

[...] Articula com todas as secretarias e cobra agilidade e respostas. Mas ele não é chefe, é um facilitador que integra: como, o que fazer, respostas. Tudo é o coordenador que cuida. É o 'marca-passo' da cidade. (Entrevistado Perfil o1, 2015).

[...] Fazer os atores 'congregarem'. Ele não é chefe de ninguém, mas um facilitador, e ajuda a delegar as tarefas, a articular entre os vários órgãos. Importou esse raciocínio da gestão de aeroportos e teve êxito na gestão da cidade. (Entrevistado Perfil 14, 2015).

(o papel do coordenador) É muito importante e delicado: 'você não é meu chefe'. Então o coordenador da sala acaba sendo um pacificador, unificador, ator muito importante para o funcionamento do COR, Sem coordenador a Sala de Controle não pode funcionar, não fica sem coordenador. (Entrevistado Perfil 20, 2015).

O processo de integração exigiu, também, ao longo do tempo, a organização das estratégias e protocolos, de maneira a criar uma convergência no modus operandi das diversas agências. Esse processo foi desencadeado também em relação a diversos outros órgãos que não estão fisicamente representados na Sala de Controle. O mais relevante exemplo deste esforço de integração remota é a atuação conjunta do COR com o Centro Integrado de Comando e Controle (CICC-RJ), centro operacional do sistema de segurança pública do Estado do Rio de Janeiro. Sobre estes protocolos, os entrevistados destacam:

Tudo que for escrito deve ser o mais simples possível -para que as pessoas entendam aquilo. (Entrevistado Perfil 33, 2015).

Há a necessidade de bons protocolos de trabalho, com adequado grau de detalhamento, apoiando a atuação conjunta das instituições e dos atores, reduzindo conflito. Pois ali já está previamente determinado quem faz o quê e o que deve ser feito em cada tipo de situação. (Entrevistado Perfil 20, 2015). 
Revista LIDER, 36(22), pp. 104-131

Em um CCC os protocolos devem estar bem definidos, para minimizar desgastes. O COR deve ser entendido como um sistema sociotécnico de homens, instituições e máquinas. (Entrevistado Perfil 25, 2015).

Para a Copa e depois da Copa se mapeou muito a cadeia de dependência: de A para B o que é preciso. Por exemplo: uma batida de carro. O que preciso da PM? da guarda municipal? dos bombeiros? da CETRIO? do guincho? como são os trâmites de cada um? O mapa de processo? Depois da Copa se realizou um fórum operacional, para avaliar departamento por departamento, serviço por serviço: como se realiza os trâmites, como se comunica com os demais atores, como melhorar, que ponto está dificultando. Tudo isso para aprimorar a integração operacional. (Entrevistado Perfil 20, 2015).

O compartilhamento de protocolos e estratégias de atuação entre instituições, no entanto, nem sempre ocorre com sucesso. Um dos exemplos é o início da implementação do COR, que demandou esforço e recursos para tentar integrar bancos de dados e sistemas que antes encontravam-se dispersos nas instituições.

Além disso, mesmo após a implementação do COR é possível observar algumas falhas de atuação. Um dos exemplos é o caso da Jornada Mundial da Juventude, 2013. Durante o trajeto do Papa Francisco, o carro do pontífice foi cercado por dezenas de pessoas, e teve sua velocidade reduzida até quase parar. Embora a situação não tenha ocasionado nenhum risco ou prejuízo para os envolvidos, isso gerou preocupação nas autoridades e na comitiva papal. De acordo com reportagem do jornal O Globo (2013b), a ocorrência se deu por conta de uma falha na comunicação entre a Secretaria de Segurança para Grandes Eventos (SESGE) e o COR:

(o secretário municipal de transportes) admitiu que o representante falhou ao não repassar o roteiro à cúpula do trânsito na prefeitura. Com isso [...] os operadores do COR trabalharam no escuro durante o percurso de Francisco do Galeão até o Centro. Para o COR, o problema foi causado pelo fato de o motorista ter errado a pista[...]. Ainda de acordo com o COR, a comitiva começou a ser monitorada no momento em que deixou o Galeão. [...] Especialistas afirmam que houve erros de planejamento. Segundo eles, a prefeitura do Rio deveria ter visto, pelas câmeras do COR, que haveria engarrafamento na rota do Papa. Ainda de acordo com os especialistas, não estava prevista uma rota alternativa para emergências, e os batedores deveriam ter evitado a passagem do carro para a pista da direita, por causa do engarrafamento ali já formado.

Situações como essa servem como parâmetros de aprendizado, e auxiliam na tomada de decisão para mudanças de estratégias a partir das lições aprendidas. Esse processo será melhor discutido no item "c" deste documento.

\subsection{Atuação fisicamente unificada e gestão horizontal}

Como ambiente de gestão de crises e que possui as ferramentas de monitoramento, os sensores urbanos e as agências integradas (física e remotamente), a Sala de Controle do COR se transformou em um grande hub de informações, um ambiente operacional a partir de onde os dirigentes das agências 
municipais monitoram e comandam as principais situações de crise vivenciadas na cidade.

Além da Sala de Controle, o COR oferece ainda outros ambientes relevantes para a gestão de crises e que são utilizadas pelos dirigentes dos órgãos municipais e de agências parceiras. Uma delas é a Sala de Imprensa, onde trabalham diariamente jornalistas dos principais meios de comunicação da cidade e em eventos de crise, a partir deste local pode-se rapidamente fazer comunicados à população. Outra das estruturas de apoio é a Sala de Crise, uma sala de reunião de onde podem ser visualizadas todas as ferramentas de monitoramento do COR, além de contar com telepresença para a residência oficial do prefeito e para a sede da Defesa Civil Municipal, o que facilita e agiliza tomadas de decisões sobre ações que necessitem do mais alto nível gerencial do Município.

Foi apresentado no referencial teórico desta pesquisa que Caragliu et al. (2011) entendem o conceito de cidade inteligente como sendo o resultado de uma soma entre infraestruturas digitais e físicas e capital humano; a esta, associa-se o lado institucional destacado por Nam \& Pardo (2011). Neste sentido, o espaço físico do COR contribuiu para essa integração. Alguns dos entrevistados destacam os benefícios do espaço unificado para a gestão urbana:

Num primeiro momento o COR era para ser apenas para chuva, alagamento e crise, mas se percebeu que se criou uma 'super' ferramenta que poderia ser usada e ajudar na rotina do dia a dia da cidade. Com o passar do tempo foi se agregando valor, trazendo outras necessidades, outros atores e outras funcionalidades. (Entrevistado Perfil 01, 2015).

A demanda para ter um CCC era para ter um espaço para reunir todos os órgãos, trazer os atores: primeiro os municipais; e poder trabalhar fisicamente mais adequados, integrados, informados. (Entrevistado Perfil 37, 2015).

A estrutura fisicamente unificada associa-se ao modelo de gestão horizontal, que nada mais é do que a aplicação do conceito integrativo mencionado no item anterior, conforme destaca o entrevistado:

No COR a atuação é horizontal, ou seja, essa atuação tradicional vertical dificultava as atuações e as relações, e o COR veio mostrar que se precisa de uma atuação horizontal. O COR não é chefe de ninguém, mas pressiona todos por eficiência. (Entrevistado Perfil 14, 2015).

A gestão horizontalizada estimula a troca de informações e a construção de protocolos de ações integradas entre as diversas áreas da gestão operacional da cidade, assim como proporciona apoio ao processo de tomada de decisões de forma compartilhada (ver Figura 3). A opção do executivo municipal pelo modelo horizontal pode ser uma singularidade deste centro de controle, em relação a outros exemplos brasileiros, em que pode existir maior verticalização hierárquica de setores, uns sobrepondo-se a outros. 
Figura 3 - Verticais de atuação do COR, identificadas pelo entrevistado.

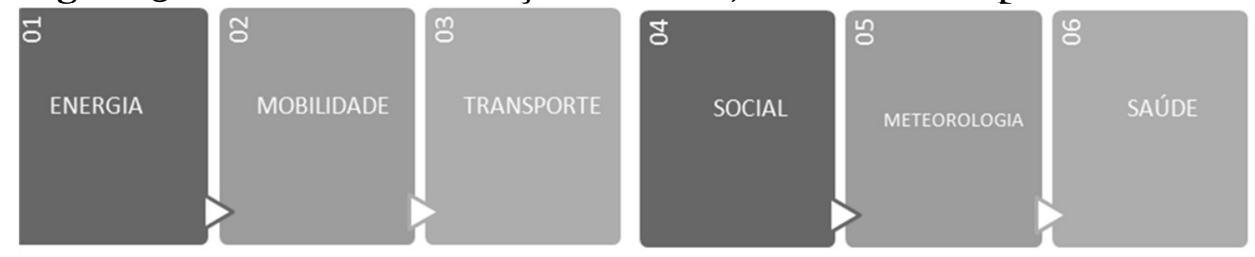

Fonte: entrevistado Perfil 16, 2015.

Vale apontar que a Figura 2, descrita pelo entrevistado Perfil 16, mostra uma ideia muito semelhante ao conceito teórico de cidade inteligente proposto pela equipe da Universidade Tecnológica de Viena (2016), anteriormente mencionado, que também secciona a estratégia em seis linhas de atuação correlatas a essas.

A implantação desse modelo trouxe, no entanto, dificuldades para a gestão. Inicialmente, o envio de funcionários das agências para trabalhar no COR era visto como punição, uma vez que a pessoa deveria deslocar-se de sua sede de trabalho e, por vezes, trabalhar em períodos extraordinários ao padrão habitual (noite, finais de semana, etc). Outra dificuldade diz respeito à adaptação dos funcionários do COR com a tecnologia mais avançada - na maioria das vezes - em relação à sua sede institucional.

Uma vez com os representantes de diferentes agências públicas reunidos na Sala de Controle, a dificuldade passou a ser como coordenar o trabalho conjunto entre eles, levando-se em conta que cada um possuía chefes e culturais organizacionais diferentes. Estes problemas foram tratados, principalmente, com a criação de uma posição funcional dentro da Sala de Controle: o coordenador de operações. Este profissional passou a atuar 24 horas por dia, como elo de integração entre os representantes das agências, realizando uma espécie de liderança por negociação com os operadores e fortalecendo, na prática, este papel de liderança integradora e articuladora proposta no projeto originário do COR.

Além disso, pode-se citar ainda a dificuldade de adaptação ao ambiente permanentemente monitorado pela mídia, o que pode exigir, na maioria das vezes, uma postura de trabalho e de comportamento diferente daquela existente em um ambiente laboral sem esse recurso.

\subsection{Atuação preventiva (e não somente remediadora)}

A repetição de problemas na cidade, os impactos e as soluções para situações de emergência são matéria-prima dentro do COR para o mapeamento de lições aprendidas e compartilhamento deste conhecimento com as agências integradas. Este processo leva em conta as múltiplas perspectivas das situações vivenciadas. Deste modo, quando uma experiência gera a necessidade de mudança de processo ou ação em nível hierárquico mais alto dentro de uma agência, a chefia operacional do COR intermedia a comunicação com a chefia do órgão em questão, a fim de alertar sobre o ajuste operacional necessário. Desta forma, é possível atuar direta e continuamente na prevenção de riscos das operações da cidade, a partir de uma perspectiva que leva em consideração as diferentes nuances da rotina urbana. Esse processo também está associado ao gerenciamento de protocolos mencionado no item anterior. Esta estratégia está, também relacionada aos estudos de Steenbruggen 
et al. (2014), para os quais o processo de coleta e análise dos dados pode resultar em melhorias na capacidade de resposta das cidades e em um incremento na qualidade de vida do cidadão. Notícias do jornal O Globo (2014) apresentam exemplos dessa atuação, tanto em relação às intempéries quanto em relação a acidentes urbanos:

às $19 h 35$, sirenes soaram em 21 comunidades do Rio, informou o Centro de Operações da Prefeitura do Rio. Os moradores foram orientados por agentes comunitários e da Defesa Civil a se dirigirem aos pontos de apoio distribuídos pelas comunidades.[...] As sirenes são acionadas caso a Defesa Civil e o Alerta Rio identifiquem que as chuvas atingiram níveis críticos (O Globo, 2014, informando sobre um temporal ocorrido em 16 de janeiro de 2014, que culminou em diversos pontos de alagamento e desabamentos de estruturas).

As lições aprendidas também alimentam as ferramentas tecnológicas do COR em camadas específicas de dados. Isso permite à equipe realizar consultas ágeis sobre ocorrências passadas para apoiar decisões sobre problemas em andamento. Por exemplo: a aplicação da lição aprendida na operação da cidade para dias de chuva se repete para diversos outros tipos de situações, como intervenções para obras (emergenciais ou planejadas), problemas de abastecimento de energia ou ocorrências no sistema de transporte, estimulando a prevenção e não apenas a atuação em reparação. Os entrevistados comentam sobre esse processo:

A medida em que um CCC trabalha, tem mais informações, mais ações já previamente estabelecidas e respostas mais conhecidas, fáceis e organizadas. Vai monitorar melhor, vai ter menos operações novas e vai ter mais capacidade de pensar e atuar no planejamento. Dentro do COR tem o planejamento de cada ação: antes, durante e depois e de forma mais ampla isso reflete na cidade. (Entrevistado Perfil 27, 2015).

Antever ao problema e, assim, ter tempo de se adaptar, aumenta a capacidade de prever, de se planejar, isso vai no sentido de resiliência (Entrevistado Perfil 24, 2015).

A cidade inteligente é a cidade que consegue aprender e se reinventar perante esse aprendizado. A cidade se reinventa, a cidade deve aproveitar as ideias, os dados [...] conhecer seus processos, sua realidade, suas limitações, os limitantes e tratar seus problemas de forma integrada. (Entrevistado Perfil 16, 2015).

O COR atua muito forte nos casos de prevenção[...] como em um dia em que o prefeito foi à mídia alertando para um perigo de tempestade, que não se realizou; até as pessoas foram mais cedo para casa, saindo antes do trabalho. Esse é o papel de um CCC: alertar para perigos e ajudar na gestão da cidade. A informação é disparada por quem a detém. Se o COR tem a informação, ele dispara para todos os atores. Se eu sei de primeira mão de um fato ou incidente, eu disparo essa informação para o COR e esse repassa para todos (Entrevistado Perfil 10, 2016, sobre a notícia abaixo relatada, publicada em fevereiro de 2016).

De acordo com a meteorologia, as condições da chuva previstas podem ser comparadas ao ocorrido em abril de 2011, quando choveu $79 \%$ do que era esperado para aquele mês [...] A prefeitura mobilizou cerca de 3.200 servidores 
da Secretaria municipal de Conservação, Defesa Civil, Rio Águas, Guarda Municipal, CET-Rio e Centro de Operações Rio. [...] Para evitar os impactos dos temporais, os esforços da prefeitura estão concentrados em vias de grande circulação[...] O Centro de Operações comunicou às concessionárias de serviços públicos e transportes coletivos - ônibus, trens e metrô - para que fiquemdeprontidão, principalmente, na hora da volta para casa. (O Globo, 2016).

Esse processo remete à política de aprimoramento constante, ressaltada por Money e Cohen (2015). De acordo com os autores, isso auxilia a aumentar a confiança no sistema e a reduzir o tempo nas respostas, ampliar sua capacidade analítica dos envolvidos. É o que Ching e Ferreira Jr. (2015) denominam "internalização" do conhecimento via estudo dos dados e consequente aperfeiçoamento. Um exemplo desse processo são as simulações realizadas com o objetivo de internalizar as estratégias necessárias, conforme exemplifica trecho de reportagem do jornal O Globo (2011a):

[O] treinamento teve como objetivo avaliar o tempo de resposta e coordenação do COR. O simulado, com a participação de 200 profissionais, teve início às $21 \mathrm{~h}$ de sábado, quando foi divulgado o primeiro boletim meteorológico (fictício) iniciando a possibilidades de chuvas fortes em 12 horas. Dentro do treinamento, às $4 \mathrm{~h}$, a cidade entrou em estado de alerta e às $6 \mathrm{~h}$ o prefeito foi acionado diante do agravamento do quadro. [...] 'o objetivo é preparar a cidade para que possa reagir melhor a essas situações variadas. Estamos muito mais preparados hoje do que no verão passado [...]' - disse o prefeito. (O Globo, 2011a, em referência a um treinamento para situações emergenciais realizado pelo COR em novembro de 2011).

Uma das controvérsias presentes nesse cenário é a de que a atuação preventiva por meio do COR não é um meio redutor de ocorrências, embora mitigador, enquanto possível identificador pontual de emergências. A ação de monitoramento é apenas parte de um processo de reestruturação urbana que deve envolver diversos outros setores em ações planejadas em médio e longo prazo. Isso é admitido pelo próprio discurso da gestão, conforme reportagens do jornal O Globo:

'O sistema de alerta não é a solução. A solução é a contenção de encosta, é o reassentamento. Mas, enquanto essas obras não ficam prontas, o sistema salvará vidas.' - admitiu o prefeito. (O Globo, 2011b).

'Se todas as pessoas se confinarem no Centro de Operações, a cidade vai ficar à deriva. O Centro de Operações é um centro de monitoramento. Temos ali equipamentos. A informação chega ao Centro de Operações e ao meu celular. As informações eu tenho. Se for me perguntado agora, não estou olhando para lugar algum e tenho as informações. [...] Ali é um centro de informações e de tecnologia. (atual Secretário Municipal de Conservação, em entrevista ao jornal O Globo, 2017b).

Outra interessante controvérsia levantada por um dos entrevistados diz respeito à questão da atuação preventiva (considerando sua limitação, conforme acima comentado) sob o ponto de vista financeiro, conforme trecho a seguir: 
A atuação preventiva é um dos resultados do modelo de gestão adotado no COR. Em geral, os atores atuam isolados e cada um cuida apenas das suas tarefas e dos seus dados. Com o COR [...] as secretarias vão agir juntas independente de burocracias e orçamentos. Agora com o COR no que tange orçamento, [...] "resolve o problema" e depois a Secretaria de Conservação faz laudo e justifica o gasto, a ação, as decisões e faz a amarração legal perante o Tribunal de Contas. [...] Uma ação integrada entre três secretarias depois das 18 horas gera custo de hora extra. Daí gera o problema: quem paga essa despesa extra? quem divide? como justificar para tribunal de contas? Ou seja, atuar de forma preventiva é muito burocrático e desestimulante. Atuar na emergência depois que a tragédia acontece é simplificado, de fácil acesso a recursos e facilita prestação de contas. Ou seja, o modelo que predomina na máquina pública é de desincentivo as ações preventivas e incentivar ações remediadoras (Entrevistado Perfil 13, 2015).

Essa é uma discussão que tange aspectos sensíveis da gestão de diversas cidades brasileiras, pois a redução de custos é algo muitas vezes buscado, independentemente das consequências dessa decisão. As questões destacadas pelo entrevistado apresentam uma estratégia considerada bastante positiva no que diz respeito à eficácia da gestão: prevenir danos a qualquer custo; por outro lado, gera a discussão de como esse processo pode ser livremente desencadeado em um momento de crise econômica nacional, em que as finanças públicas tendem a estar fragmentadas e a distribuição de recursos deve ser ainda mais planejada - em especial considerando a situação do Estado do Rio de Janeiro, que nos últimos meses vem apresentando dificuldades de organização do orçamento, em negociação com a União.

\subsection{Comunicação como ferramenta operacional}

Diferentemente do que acontece na maioria dos órgãos públicos brasileiros, a equipe de comunicação social do COR não tem como foco principal a divulgação de notícias institucionais para os meios de comunicação. No COR, a comunicação é utilizada como uma ferramenta operacional para informar os cidadãos - através de uma espécie de agência de notícias em tempo real - sobre as operações da cidade, para que planejem melhor suas rotinas e, em situações emergenciais, saibam como manter-se em segurança. As mesmas informações que as equipes operacionais do COR tem acesso na Sala de Controle podem ser consultadas e divulgadas pelos jornalistas da Sala de Imprensa. Este trabalho envolve o disparo de comunicados via redes sociais (Twitter, Facebook e Instagram), as parcerias com aplicativos móveis de mobilidade urbana (Waze, Moovit eou pelo aplicativo COR.Rio, por exemplo) e o relacionamento com os meios de comunicação da cidade (principalmente rádios, TVs e websites de notícias). Neste aspecto, as rádios se destacaram por sua característica de capilaridade urbana, comunicação em tempo real e interação com a audiência. De acordo com reportagem do jornal O Globo (2017b), atualmente cerca de 60 mil cidadãos recebem mensagens do COR via SMS, e mais de 800 mil perfis seguem o COR nas redes sociais. Em situações de emergência, os comunicados feitos pelo COR podem chegar a mais de sete milhões de perfis em 24 horas.

A comunicação é bilateral, ou seja, o cidadão também pode ofertar informações, além de ser receptor. Ao identificar uma situação que exija atuação do 
COR, o cidadão pode entrar em contato com o órgão a partir de um dos canais de comunicação. Nos aplicativos de trânsito, por exemplo, toda vez que um usuário notifica sobre problemas de mobilidade esta notificação pode ser imediatamente visualizada (de forma anônima) na Sala de Controle do COR. A utilização do aplicativo Waze integrado ao COR, em especial, rendeu à cidade do Rio de Janeiro uma menção como referência mundial no primeiro encontro do W10 (atualmente, denominado Connected Citizens Program), grupo criado pela empresa proprietária do aplicativo com as cidades que melhor usam a colaboração dos cidadãos na gestão das operações urbanas (Terra, 2014).

Um trecho de reportagem do jornal O Globo (2013a) apresenta o comentário de um dos editores do aplicativo VaiRio, sobre a forma com que ocorre essas ações:

Repórteres baseados no Centro de Operações Rio [...] vão mandar alertas sobre tudo o que acontece no trânsito da cidade[...]. Como eles têm acesso aos telões com imagens no Rio, podem sugerir rotas mais rápidas. O aplicativo vai realmente ajudar os cariocas a fugir dos engarrafamentos

Essa estratégia sugere a construção de uma relação 'ganha-ganha': enquanto os cidadãos podem receber úteis informações sobre a cidade, que os ajudam a se planejar e tomar decisões, o COR conta com 'fiscais' nas ruas, que alertam o time operacional da prefeitura ao primeiro sinal de problemas, gerando acionamentos de serviços e otimizando o tempo de resposta das agências. Ênfase no cidadão também é fundamental neste processo, conforme um dos eixos da cidade inteligente proposto pela TUVIEN (2016), e conforme Citrigno et al. (2014), que reforçam esta ideia afirmando que aspectos ligados a inclusão e capacitação dos cidadãos e dos agentes envolvidos na operação da cidade são fundamentais para a inteligência urbana. Ambos os grupos, de acordo com os autores, devem tornar-se os principais tutores do território, participando na detecção de situações críticas no território urbano.

Por um lado, esta ação auxiliou muito o COR a cobrar respostas mais imediatas às agências de serviços públicos. Por outro, ela inseriu definitivamente os meios de comunicação como um importante ator nas operações da cidade, que além de informar ao cidadão, passaram a ser essencial fonte de informação para orientar o trabalho da Sala de Controle do COR. Os entrevistados apontam os benefícios dessa transformação:

Antes do COR a informação era desencontrada, informações dispersas, não se sabia o que iria acontecer, quem iria falar, onde iria falar, não se tinha uma pesquisa de dados de chuvas, mesmo a parte de pluviômetros era muito aquém do que hoje". (Entrevistado Perfil 19, 2015).

O COR de um lado recebe apoio das concessionárias, por outro lado o COR recebe ali dentro as rádios e TV, a mídia. O que dá transparência, credibilidade e carimbo de que essa é uma informação oficial, de confiança. Quando o COR divulga uma informação isso significa que a prefeitura já sabe do problema e já está atuando (Entrevistado Perfil 01, 2015).

O COR trabalha muito em ofertar uma informação padronizada para dar mais credibilidade para essa informação. O COR passa veracidade na informação [...] Por vezes o ouvinte informa o jornalista da rádio sobre algum incidente e esse jornalista repassa ao assessor de imprensa do COR. Eles checam a 
informação e, se confirmada, retornam ao jornalista para este informar o seu público. (Entrevistado Perfil 18, 2015).

Foi realmente muito importante a imprensa ter ido para dentro do COR. Inicialmente as rádios recebiam a informação e informavam as pessoas. Inclusive isso amadureceu, e as pessoas avisam as rádios e essas passam também a avisar o COR das ocorrências, um amadurecimento. (Entrevistado Perfil 19, 2015).

Uma importante dificuldade encontrada pela equipe do COR na criação deste serviço de informações em tempo real foi a implementação de novos processos de obtenção de informações primárias e validação das mesmas, antes de serem divulgadas. Isso ocorreu porque cada agência pública integrada ao COR possui sua própria assessoria de comunicação que, por ética de relacionamento interagências, demandavam validação de cada informação relativa a cada instituição integrada, antes da divulgação. A dificuldade objetiva nesta mudança no processo de comunicação para os cidadãos (proposta pelo COR) era que o tradicional tempo de resposta das assessorias de comunicação das agências integradas estava aquém do necessário para que o COR realmente implantasse um serviço de informações em tempo real. Além disso, muitas das informações sobre serviços públicos que o COR passou a comunicar aos cidadãos não eram comunicadas anteriormente pelas agências responsáveis por estes serviços. Estas dificuldades foram tratadas através de alinhamentos entre as diferentes equipes de comunicação envolvidas e, ao mesmo tempo, com acordos feitos diretamente entre o chefe-executivo de operações do COR e os dirigentes das agências públicas.

Observando o caso estudado, o COR tende a apresentar quatro benefícios para a gestão operacional da cidade, como apresentado na Figura 4. 
Figura 4. Tendência de benefícios gerados pelo COR.

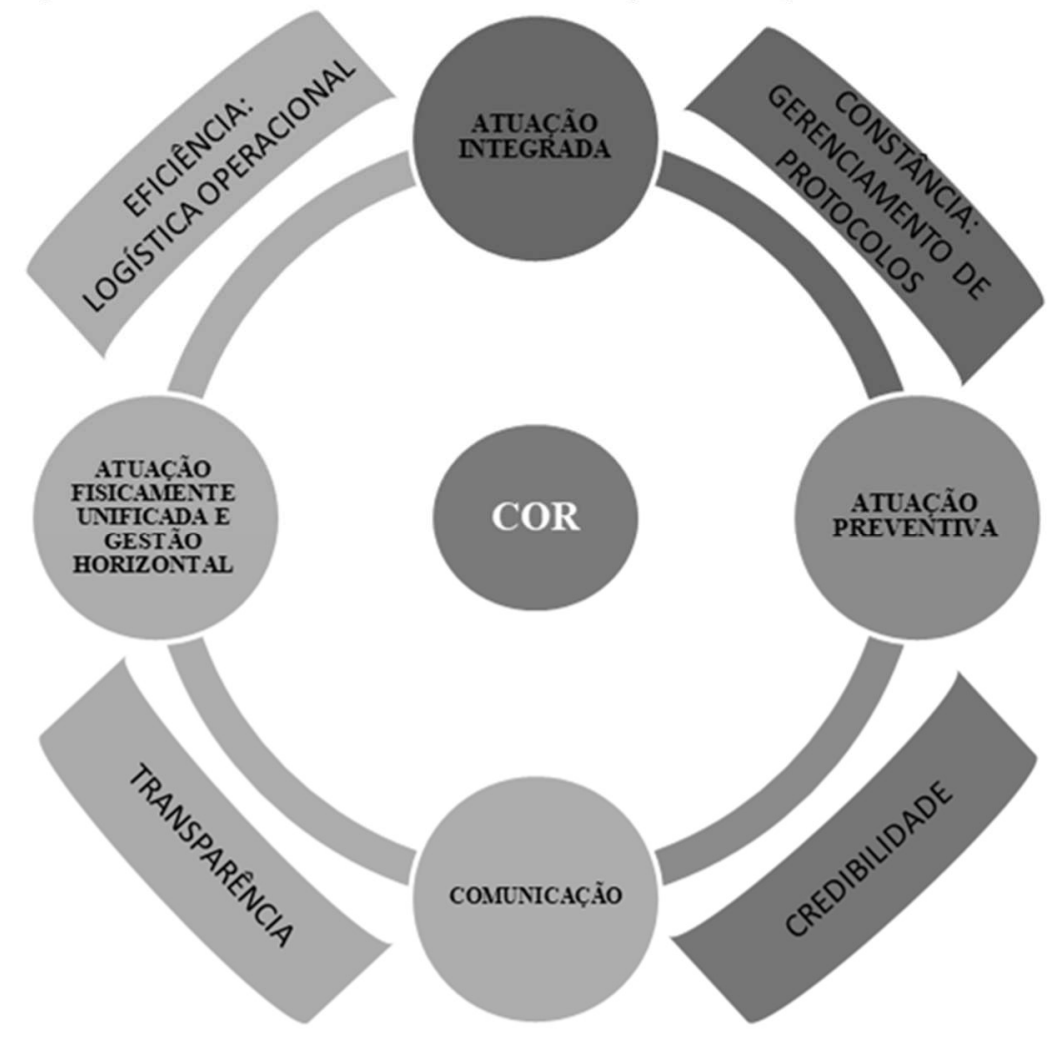

Fonte: elaborado pelos autores (2017).

\section{CONSTÂNCIA NO GERENCIAMENTO DE PROTOCOLOS}

A ampliação de dados e integração da informação dos atores reflete em resultados na gestão urbana apenas com uma ampla revisão dos processos de ações conjuntas e dos protocolos. No caso do Rio de Janeiro esses protocolos tiveram que ser aprofundados e contar com a colaboração de todos os envolvidos, cada um detalhando sua parte, suas ações e sua demanda sobre o outro departamento para o caso de uma demanda integrada.

Essa nova dinâmica envolvendo o gerenciamento dos protocolos reflete na dinâmica de atuação integrada e preventiva, conforme observado na Figura 4. Dessa forma, além de fortalecer a visão do "ganha-ganha" entre os atores, evita-se tentativas frustradas. Ou seja, com a revisão constante dos protocolos pode-se fazer uso das lições aprendidas para responder melhor às demandas no futuro. Essa ideia ratifica o pensamento de Klauser et al. (2014), no que diz respeito à interligação entre os dados, tecnologia e pessoas, num processo de reorganização; e de Toppeta (2010), quanto à reorganização de processos e a redução da burocracia.

\section{EFICIÊNCIA LOGÍSTICA OPERACIONAL}

A logística operacional urbana apresenta externalidades (fatores fora do controle dos gestores) que podem dificultar respostas aos problemas locais. A atuação fisicamente unificada é um fator que tende a facilitar respostas integradas; 
isso ocorre uma vez que grande parte dos atores estão próximos, conhecendo a fundo a atuação um do outro. Essa atuação integrada soma-se à gestão horizontal, no que tange a atuação conjunta das várias frentes da cidade para minimizar os problemas ocorridos. A busca de eficiência na logística urbana deve necessariamente envolver a coleta e análise dos dados visando melhorar com as lições aprendidas (Ching \& Ferreira Jr., 2015) e ampliar a capacidade de ação preventiva e capacidade de resposta remediadoras da cidade (Steenbruggen et al, 2014).

\section{TRANSPARÊNCIA, ASSOCIADA À CREDIBILIDADE}

A comunicação - no sentido de "colaboração" - se mostrou, no caso estudado, um fator bastante relevante. A comunicação interna do Centro de Operações informa e aproxima atores, inclusive estimulando a confiança; a comunicação externa com a sociedade, por sua vez, visa o envio e recebimento de informações em tempo real. Conforme apresentado na figura 4, a comunicação associada à atuação preventiva resulta em maior credibilidade institucional, uma vez que oferece instrumentos para que o cidadão seja um ator urbano, trabalhando conjuntamente na prevenção de ocorrências. A associação da comunicação com o sistema unificado de gestão pode colaborar, ainda, para que exista mais transparência nas relações verticalizadas.

\section{CONSIDERAÇÕES FINAIS}

As cidades que procuram caminhar para a lógica das cidades inteligentes resultam de uma soma de diversos fatores: tecnologia, uso inteligente da informação, aproveitamento do potencial do capital humano, uso inteligente dos recursos, entre outros. Na prática, as realidades são muito diferentes e singulares, o que inviabiliza pensar em padrões ou modelos conceituais rigidamente construídos. No entanto, a literatura aponta para traços de inteligência que podem ser alcançados -ao menos parcialmente- com estratégias inovadoras e arranjos político - institucionais.

Neste sentido, uma reflexão sobre a gestão urbana brasileira recente sugere dificuldade neste processo, no sentido de obstáculos na integração e capacitação dos atores envolvidos com a gestão pública, bem como na descontinuidade de políticas públicas. O mercado tende a oferecer produtos bastante inovadores e dispendiosos para cidades inteligentes, que muitas vezes acabam sendo vendidos como soluções completas para os problemas urbanos. No entanto, é necessário compreender que cada cidade é singular, e que o caminho para a inteligência acompanha essas particularidades (ainda que lições aprendidas possam ser compartilhadas entre diferentes realidades).

Por fim, vale a pena retomar o destaque de Calderón, López e Marín (2018), sobre os desafios dos países latino-americanos referentes à gestão urbana e as limitações financeiras e trazer a digitalização de dados e o uso de TICs como um caminho para melhorar a eficiência na gestão pública, otimizando os recursos públicos, equipamento, capital humano eimpactando na qualidade de vida do cidadão.

Esta pesquisa investigou uma estratégia de inteligenciamento urbano inovadora em consideração à realidade brasileira. Observou-se que o COR é reconhecido - principalmente internamente- como um fomentador de ajustes para a gestão urbana do Rio de Janeiro. Antes dessa implantação, a Prefeitura do Rio de Janeiro apresentava uma gestão menos integrada, com os departamentos 
trabalhando de forma mais isolada, o que resultava em dificuldades para identificar os responsáveis por situações que exigiam ações rápidas e com múltiplos atores envolvidos. $\mathrm{O}$ fomento à integração de atores, ao monitoramento através de dados e imagens, e às novas tecnologias e ferramentais de comunicação são relevantes para a gestão da cidade e para o aumento da capacidade de resiliência urbana.

Deve-se ressaltar que não basta defender o discurso de cidade inteligente e manter infraestrutura precária, ou proporcionar uma maior recepção de informações sobre um problema, mas não conseguir ofertar respostas adequadas. Um dos desafios enfrentados por aqueles que tocam na temática das cidades inteligentes é a separação entre discurso e ação, o risco de ficar apenas no discurso é presente e muitas vezes a ação apresenta um elevado grau de abstração ou ser pouco palpável, o que dificulta a prática. Dessa forma, para que a integração seja constantemente aprimorada, torna-se necessário a análise contínua de feedbacks das operações, como ferramenta de aperfeiçoamento do engajamento e da atuação. Este é um papel relevante que os centros de operações urbanos podem ocupar, enquanto impulsionadores de melhorias nas operações da cidade, não apenas nas respostas em tempo real, mas também no planejamento para mudanças em procedimentos e rotinas.

Isso é uma mudança de comportamento, de comprometimento dos atores envolvidos, além de estimular a busca por antecipar-se perante os problemas e não a simples postergação ou a negação dos mesmos. Neste sentido, pensando em termos de cultura de trabalho, o COR pode servir de exemplo metodológico, especialmente no que diz respeito a ações interagências, análises integradas de riscos, elaboração de contingências, desenvolvimento de protocolos de resposta conjunta e os fóruns operacionais.

Esta pesquisa limita-se a investigar um caso único, particularmente complexo e que envolve uma série de variáveis socioeconômicas, geográficas, culturais e sobre o contexto envolvido, e, portanto, não pode generalizar a respeito de nenhum dos pontos de transformação aqui analisados. Como sugestão para estudos futuros, pode-se desenvolver o mesmo método de análise em outras realidades, para fins comparativos.

\section{REFERÊNCIAS}

Alizadeh, T. (2017). An investigation of IBM's Smarter Cites Challenge: What do participating cities want? Cities, 63, pp. 70-80. Recovered on May, 2020, from http://dx.doi.org/10.1016/j.cities.2016.12.009

Batista, M. de M.; Dallabona, T. M.; Mello, S. C. B de. (2016). Smartsurveillance em Aplicações Recentes no Brasil: Um Estudo de Caso nas Cidades de Recife e Curitiba. Revista de Gestão e Secretariado -GeSec, 7 (2), 104-137.

Botelho, L., L., R.; Cunha, C. C. de A.; Macedo, M. (2011). O método da revisão integrativa nos estudos organizacionais. Gestão e Sociedade, 5(11), 121-136. Recovered on September, 2017, from http://www.gestaoesociedade.org/gestaoesociedade/article/view/1220/906

Bruno, F. (2013). Vigilância hoje. Entrevista concedida a Eduardo de Jesus. Dispositiva, 2(1), 75-82. 
Calderón, M., Lópes, G., \& Marín, G. (2018). Smartness and Technical Readiness of Latin American Cities: A Critical Assessment. IEEE Access, 6. Recovered on May, 2020, from 10.1109/ACCESS.2018.2864218

Caragliu, A.; Del Bo, C. \& Nijkamp, P. (2011). Smart Cities in Europe, In: Journal of Urban Technology, 18(2), 65-82.

Cardoso, B. de V. (2010). Todos os Olhos: Videovigilâncias, videovoyeurismos e (re)produção imagética na tecnologia digital. (Tese de doutorado em Sociologia e Antropologia) Rio de Janeiro: UFRJ.

Citrigno, S.; Graziano, S.; Sacca, D. (2014) Cooperation of Smart Objects and Urban Operators for Smart City Applications. Recovered on February, 2016, from http://ceur-ws.org/Vol-1156/paper4.pdf

COR - Centro de Operações Rio. (2017). http://cor.rio/

Ching, T. Y. \& Ferreira JR., J. (2015). Smart Cities: Concepts, Perceptions and Lessons for Planners. In: Geertman, S.; Ferreira JR., J.; Goodspeed, R.; Stillwell, J. Planning support systems and smart cities: lecture notes in geoinformation and cartography (145-168). Springer International Publishing Switzerland.

Couto, J. A. C. \& Soares, J. A. de M. (2012). Lições de gerenciamento de crises. Brasília. Recovered on November, 2012, from http://www.planalto.gov.br/gsi/saei/publicacoes/licoesGerenciamentoCrises.pdf

Cunha, M. A.; Przeybilovicz, E.; Macava, J. F. M.; Burgos, F. (2016). Smart cities: transformação digital de cidades. São Paulo : Programa Gestão Pública e Cidadania - PGPC, FGV. Recovered on May, 2020, from http://ceapg.fgv.br/sites/ceapg.fgv.br/files/u6o/smart_cities_bra_versao_f inal.pdf

Durães, D. F. M. (2008). Arquitectura de sistema de vigilância integrada. (Dissertação de mestrado). Universidade do Porto, Porto.

Folha de São Paulo. (2012). Rio testa sistema pioneiro de tecnologia em centros urbanos. Notícia publicada em 16 de março de 2012. Recovered on May, 2016, from

http://www1.folha.uol.com.br/tec/2012/o3/1060783-rio-testa-sistema-pioneirode-tecnologia-em-centros-urbanos.shtml

Giffinger R. et al. (2007) Smart Cities: Ranking of European Medium-Sized Cities. Centre of Regional Science (SRF), Vienna University of Technology. Recovered on June, 2015, from http://www.smart-cities.eu/pressressources.html

Gil, A. C. (2008). Métodos e técnicas de pesquisa social (6 $6^{\mathrm{a}}$ ed.). São Paulo: Atlas. Hampapur, A.; Brown, L.; Connell, J.; Pankanti, S.; Senior, A., \& Tian, Y. (2003). Smart Surveillance: Applications, Technologies and Implications. In: IV ICICS - International Conference on Information, Communication \& Signal Processing, 15-18 December, Singapore.

Harvey, D. (2005). A produção capitalista do espaço. São Paulo: Annablume.

Kanashiro, M. M. (2009). Os olhos que atravessam a cidade e deslocam os sentidos. In: Simpósio 2009 PUC PR Surveillance in Latin America. Recovered on October, 2012, from http://www2.pucpr.br/ssscla/anais.htm

Kitchin, R. (2014). The real-time city? Big data and smart urbanism. GeoJournal, $79,1-14$. 
Klauser F.; Paasche, T.; \& Söderström. O. (2014). Michel Foucault and the smart city: power dynamics inherent in contemporary governing through code. Environment and Planning D: Society and Space, 32, 869-885.

Komninos, N. (2011). Intelligent cities: Variable geometries of spatial intelligence. Intelligent Buildings International, 3,172-188.

Llacuna, M. M.; Colomer-Llinàs, J.; \& Meléndez-Frigola, J. (2015). Lessons in urban monitoring taken from sustainable and livable cities to better address the Smart Cities initiative. Technological Forecasting \& Social Change, 90,.611622. Recovered on September, 2016, from http://www.sciencedirect.com/science/article/pii/S0040162514000456

Nacaratti, M. A. (2008). Os cenários de mudanças climáticas como novo condicionante para a gestão urbana: as perspectivas para a população da Cidade do Rio de Janeiro. XVI Encontro Nacional de Estudos Populacionais, Caxambu- MG - Brasil, 29 de setembro - 03 de outubro de 2008.

Nam, T. \& Pardo, T. A. (2011). Smart city as urban innovation: Focusing on management, policy, and context. In Proceedings of the 5th International Conference on Theory and Practice of Electronic Governance - ICEGOV'11, New York, NY, EUA. 185-194.

O Globo. (2011 ${ }^{\mathrm{a}}$, 04 de agosto). Acidente ativa plano de emergência no Rebouças. Recovered on May, 2016, from http://acervo.oglobo.globo.com/?service=printPagina\&imagemPrint $=\mathrm{http} \%$ 3A\%2F\%2Fduytok3aayxim.cloudfront.net\%2FPDFs_XMLs_paginas\%2Fo_g lobo.com.br

O Globo. (2011b, 31 de janeiro). Chuvas ainda oferecem riscos para o verão dos cariocas. Recovered on July, 2017, from http://riocomovamos.org.br/site/wpcontent/uploads/2015/09/clip_janeiro2011.pdf

O Globo. (2011c, 07 de novembro). Licitação de obras contra enchentes sai dia 23. Recovered on May, 2016, from http://acervo.oglobo.globo.com/?service=printPagina\&imagemPrint $=\mathrm{http} \%$ 3A\%2F\%2Fduytok3aayxim.cloudfront.net\%2FPDFs_XMLs_paginas\%2Fo_g lobo.com.br

O Globo. (2013 ${ }^{\mathrm{a}}, 14$ de abril). Uma ajuda para escapar de engarrafamentos. Recovered on May, 2016, from https://oglobo.globo.com/rio/o-globo-lancaaplicativo-de-celular-com-condicoes-do-transito-8109307

O Globo. (2013b, 23 de julho). Papa imóvel.

O Globo. (2014, 17 de janeiro). Chuva paralisa sistema de transporte no Rio. Recovered on May, 2016, from http://acervo.oglobo.globo.com/?service=printPagina\&imagemPrint $=\mathrm{http} \%$ 3A\%2F\%2Fduytok3aayxim.cloudfront.net\%2FPDFs_XMLs_paginas\%2Fo_g lobo.com.br

O Globo. (2016, o6 de fevereiro). Eduardo Paes faz alerta a população sobre a previsão de chuva muito forte nesta quinta-feira. Recovered on May, 2016, from https://oglobo.globo.com/rio/eduardo-paes-faz-alerta-populacao-sobreprevisao-de-chuva-muito-forte-nesta-quinta-feira-15248483\#ixzz4nJZPFilk

O Globo. (2017 ${ }^{\mathrm{a}}, 21$ de junho). Centro de Operações Rio lança campanha para o envio de alertas de emergência através de mensagem no celular. Recovered 
Hodja, Martins \& Dallabona | Da cidade inteligente à inteligência nas operações

urbanas

on July, 2017, from https://oglobo.globo.com/rio/centro-de-operacoes-rio-lanca-campanha-para-enviode-alertas-de-emergencia-atraves-de-mensagem-no-celular21526140\#ixzz4nOhKoBjQ

O Globo. (2017b, 21 de junho). Boletins do Centro de Operações não alertavam para riscos de fortes alagamentos. Recovered on July, 2017, from https://oglobo.globo.com/rio/boletins-do-centro-de-operacoes-nao-alertavam-parariscos-de-fortes-alagamentos-21502758\#ixzz4nOimwoKC

Queiroz, R. J. N. (2010). Implantação de um centro de operações em tempo real de um agente de transmissão do sistema interligado nacional. (Monografia de Graduação em Engenharia Elétrica). Escola Politécnica - UFRJ, Rio de Janeiro.

Smart city Business. (2020). Smart city business Expo Brasil. 2020. Recovered on May, 2020, from http://smartcitybusiness.com.br/home/

Steenbruggen, J.; Tranos, E. \& Nijkamp, P. (2015). Data from mobile phone operators: A tool for smarter cities? Telecommunications Policy, 39(3-4), 335-346 Recovered on September, 2015, from http://dx.doi.org/10.1016/j.telpol.2014.04.001.

Terra. (2014). SP e Rio estão entre as cidades que mais usam o Waze. Notícia Publicada em 24 de outubro de 2014. Recovered on September, 2017, from https://www.terra.com.br/noticias/tecnologia/sp-e-rio-estao-entre-ascidades-que-mais-usam-owaze,73c4b8879c249410VgnVCM20000099cceboaRCRD.html

Toppeta, D. (2010). The Smart City Vision: How Innovation and ICT Can Build Smart, "Livable", Sustainable Cities. The Innovation Knowledge Foundation, 2010. Recovered on December, 2015, from http://www.thinkinnovation.org/file/research/23/en/Toppeta_Report_005_2010.pdf.

Wacquant, L. (2002). Corpo e alma: notas etnográficas de um aprendiz de boxe. Rio De Janeiro: Editora Relume Dumará.

$\mathrm{Xu}, \mathrm{H} .$, \& Geng, X. (2019). People-Centric Service Intelligence for Smart Cities. Smart Cities, special issue. Recovered on May, 2020, from https://doi.org/10.3390/smartcities2020010

Yin, Robert K. (2001). Estudo de caso: planejamento e métodos ( $2^{\mathrm{a}}$ ed.) São Paulo; Bookman. 